\title{
How and what others are doing in competitive intelligence: outsourcing model
}

\author{
Marié-Luce Muller \\ IBIS Business and Information Services \\ mlm@ibis.co.sa \\ www.ibis.co.sa
}

\section{Introduction}

The columns on Competitive Intelligence (CI) for 2009 focus on models for CI and how companies use such models. As stated in the previous columns, seldom do two CI practices resemble one another. The reasons are multiple but perhaps the most logical reason is that no two companies are the same. They differ in size, the industry they play in, the manner in which they compete, their competitive strategies, the people and skills and many other reasons. The previous article described the various models, including the centralised, decentralised and hybrid models. The placement of the CI unit within a company was also discussed. The previous article touched upon the outsourced CI model. This article will look into the outsourced model in more detail.

\section{Background}

Outsourcing has become a growing trend and strategy of companies to enable company managers to focus more on core business (Salonen and Pirttimaki 2005). A 2006 SCIP report revealed that more than $50 \%$ of all competitive intelligence (CI) professionals outsource some portion of their CI efforts, making this a major need in the industry (SCIP 2006). According to Comai (2008), a CI function can be divided into two main activities, namely an operations part (delivering an intelligence product and including activities such as collection, analysis and communication of intelligence) and a CI administrative part (that includes the activities, actions and resources needed to manage the operational activity.) Although these two aspects have to be well-integrated to yield CI effectiveness, it is typically the operational part or parts of the operations of CI that are outsourced (Comai 2008). Outsourcing CI has become a global phenomenon and is also prevalent in South Africa.

\section{Outsourced CI activities}

Glitman (2007) states that parts of the competitive intelligence process have always been outsourced. The previous article stated that, often, the information collection aspect of CI is outsourced (Salonen and Pirttimaki 2005). This is often done partly because there is a limit to what a company can source internally. He says, often employees are not allowed to elicit certain information from competitors, thereby making the CI capability dependent on external sources and gatherers of certain information. Typically, outsourcing could also be done on a project basis, be it a competitive intelligence or research project, product testing, or related initiatives (Himerlfarb 2007).

It is not only information collection that is outsourced. Companies often outsource other typical CI activities including tracking and scanning for events in the competitive environment, commissioning strategic studies and a whole range of assignments. Some companies have annual contracts with one or more outside providers, while others use 
outside resources for only one or two projects per year. There are also companies that use outsourcing only for projects with which the company has no internal expertise, such as a new market analysis or competitor profile. Contract types include annual and retainer contracts and project agreements (Wunderlin 2007).

Ad hoc outsourcing (e.g. for certain once-off projects) has its disadvantages (Eaton 2003). Typically a CI research company is approached which then focuses solely on the scope provided, does the research and delivers the results, and withdraws. The company is not strengthened and the research company's own new knowledge of the particular market or competitive situation is seldom called upon again for the benefit of the client company. This is not an efficient approach to outsourcing of CI. Although the client company might receive a high quality service in a short time delivered by the best CI specialists, there is little longterm value. The company that outsources gets a higher quality service at a lower cost, primarily because of the economies of scale for the external company and that company's significant advantages in hiring and keeping expert employees in the outsource function. Companies can gain access to very experienced individuals with a lifetime of contacts.

\section{Reasons for outsourcing}

The reasons for and benefits of outsourcing are many. The main motivation has been corporations seeking to reduce costs by contracting out services and activities traditionally provided in-house and to gain a competitive advantage by seeking differentiation and efficiencies (Salonen and Pirttimaki 2005). The rationale of this movement is that outsourcing is cheaper and more efficient. It also allows companies to have an enhanced focus on those things they can do better in-house (Hendry 1999). There is an extensive body of literature that identifies achieving greater economies of scale as a prime reason for outsourcing (Currie and Willcocks 1997; Finlay and King 1999). A PriceWaterhouseCoopers study (1999) examining the outsourcing practices of more than 100 key organisations concluded that the majority of companies outsource primarily to save on overheads through short-term cost savings.

Another reason is capacity related. Sometimes, for a number of reasons, even the most effective CI capabilities require additional capacity. Typically, there could be added workload and pressure to cut cost. During the interviews for the SCIP project (SCIP 2006), most managers indicated that outsourcing CI activities provides value to them. Their key reasons for outsourcing included the following (Wundelin 2007):

- Obtaining particular industry expertise

- Using outside resources instead of expanding staff

- Obtaining objective results or checking internal thinking

- Ensuring that ethical and legal guidelines are followed in obtaining certain types of information.

Participants specifically cited primary research, conference collection and secondary-source monitoring as especially valuable outsourcing applications. They save practitioner time and leverage assets and knowledge. Other key benefits of outsourcing included the following (Eaton 2003; Wunderlin 2007):

- Avoiding competitive blind spots

- Entering new markets where internal managers do not have expertise

- Checking internal assumptions

- Access to specialists who often have vast contact and a valuable broader view of the competitive environment. They often create a larger strategic context into which the competitive data are placed 
- Outsourcing CI allows for more unique insights being gathered and developed thought contact with external sources

- Building a longer-term CI capability is one of the major advantages of outsourcing. Having a long-term relationship with an external third party consulting resource means that that resource is available to build a larger awareness capability throughout the company that contracts for its services

- CI researchers can also assist with assessing the implications of events. In other words, they go beyond gathering and integrating data and information and move to the interpretative and analytical part. Often, such research companies have exposure to a range of industries, competitive forces and trends that could enrich the information set more than would have been the case had the company done its own CI.

Outsourcing could be seen as a tool for improving competitive advantage rather than just a cost-saving measure. Smith (2006) argues further that because outsourcing often is still viewed as a 'last resort, its use can confuse your competition into making false assumptions and taking tactical and strategic missteps.'

\section{Risks associated with outsourcing}

Uncertainty and risk of failure exist every time a company is considering outsourcing a function (Salonen and Pirttimaki 2005). Outsourcing often involves an element of risk and companies should be knowledgeable on measures to control these risks (Glitman 2007). Glitman mentions another interesting aspect and that is to outsource certain parts of CI to geographies where the fees are less, for example China and India. These countries have the capabilities to do such work. This gives companies a new scope in terms of collection and analysis capabilities.

The risks associated with outsourcing can be typically categorised under the following (Glimtan 2007; Salonen and Pirttimaki 2005):

- Confidentiality and intellectual property

- Revealing strategies to the competitor

- Relinquishing control over gathering and analysis practices, potentially leading to damage associated with unethical or illegal methods by the contractor.

There are a number of ways to minimise risk, including the building of a trust relationship with the vendor and creating transparency, that might prevent sensitive information from falling in the hands of competitor (Glitman 2007). There is also the risk associated with third parties. Involving third parties may mean that ethics and legal restrictions become stretched or violated, so the companies must be clear beforehand what the ethical and legal boundaries are in terms of collection methods. In 2001, Proctor \& Gamble (P\&G) learned a hard lesson in this regard. It was forced to reach a settlement with its competitor, Unilever after admitting that its information collection activities transgressed its ethical code. These activities included going through Unilever's trash in search of competitor information (Weiss 2001). P\&G did not do the information collection itself but outsourced it to another company without making sure that this company knew $P \& G$ 's principles and policies.

Ethical and legal risk can be minimised by being clear about the company's ethical approach and establishing clarity regarding the legal ways to gather information and interact with sources (Glitman 2007). Himelfarb (2007) proposes another tool to screen and select outsourcing partners, namely due diligence. The competitive intelligence due diligence checklist for screening and selecting the vendor or supplier includes understanding its full range of capabilities, identifying past similar projects and manufacturing experiences and identifying the outsourcer's financial stability to avoid the risk that it will fail to fulfil its part 
of the outsourcing contract.

\section{Conclusion}

Although outsourcing CI or aspects of CI are options for companies to consider, care must be taken to identify the associated risks and to manage such risks. It is also worthwhile to consider developing a long-term view on outsourcing in order to gain maximum value from a partnership with a CI research company. The benefits of CI increase over time. Conversely, the benefits of ad hoc CI projects are brief. Capacity, price and quality are the main considerations that play a role in outsourcing (Hannula and Pirttikaki 2003.)

\section{References}

Comai, A. 2008. Benchmarking with the world-class competitive intelligence model [Online]. Available WWW: http://competitiveintelligence.ning.com/profiles/blogs/2036441:BlogPost:5621. Accessed 3 August 2009.

Currie,W. and Willcocks, L.P. 1997. New strategies in IT outsourcing: major trends and global best practice. Report, Business Intelligence Ltd, London. (December).

Eaton, E. 2003. Competitive intelligence: should it be permanently outsourced now? [Online]. Available WWW: www.eleanoreaton.com. Accessed 30 July 2009.

Finlay, P.N. and King, R.M. 1999. IT outsourcing: a research framework. International Journal of Technology Management 17(12):109-128.

Glitman. 2007. Outsourcing competitive intelligence. Competitive Intelligence Magazine 10 (2).

Hannula, M. and Pirttikaki, V. 2003. Business intelligence empirical study on the top 50 Finnish companies. Journal of American Academy of Business, Cambridge, 2(2).

Hendry, J. 1999. Culture, community and networks: the hidden cost of outsourcing. European Management Journal 13(2):193-200.

Himelfarb, D. 2007. Due diligence for outsourcing. Competitive Intelligence Magazine 10 (4).

Salonen, J. and Pirttimaki, V. 2005. Outsourcing a business intelligence function. Frontiers of e-business research.

SCIP (Society for Competitive Intelligence Professionals). 2006. State of the art: competitive intelligence (SCIP commissioned research report). Competitive Intelligence Foundation.

Smith, J. 2006. Outsourcing as a strategic tool. Competitive Intelligence Review 7(3):70-74.

Weiss, A. 2001. CI ethics: how far can primary research go? Competitive Intelligence magazine 4(6).

Wunderlin, C. 2007. Outsourcing your CI needs. Competitive Intelligence Magazine 10(2). 
Marié-Luce Muller is a consulting competitive intelligence analyst with IBIS Business and Information Services (Pty) Ltd, a leading Pretoria-based CI consultancy. She has a distinguished career in competitive intelligence. Her primary experience lies in assisting companies in honing their CI capabilities. She also performs tracking and scanning activities on behalf of companies. MariÃ@)-Luce has published many articles on competitive intelligence (CEO Magazine, Finance Week, Business Week, Beeld, Die Burger, and the South African Journal of Business Management), including an article on South Africa as an emerging CI player, which was published in an international publication of the Society of Competitive Intelligence Professionals (SCIP). She has also published a series of booklets on competitive intelligence (Nuts and Bolts business series, published by Knowledge Resources) and is a member of a research team participating in an international study of competitive intelligence practices among exporting companies. Previously, she was involved in research into the status of competitive intelligence practices in South Africa. A member of SCIP, she holds a postgraduate degree from the University of Stellenbosch.

ISSN 1560-683X

Published by InterWord Communications for Department of Information and Knowledge Management, University of Johannesburg 